\title{
To Set your watch by the Sun
}

\section{Willis E. Johnson}

To cite this article: Willis E. Johnson (1911) To Set your watch by the Sun, Journal of Geography, 10:2, 68-70, DOI: $10.1080 / 00221341108985646$

To link to this article: http://dx.doi.org/10.1080/00221341108985646

曲 Published online: 20 May 2008.

Submit your article to this journal

Џ Article views: 3

Q View related articles $₫$ 
30. The United States uses $1 / 3$ of the world's raw silk. Why so much?

31. What state and what city lead in silk manufacturing? Reasons?

32. Pennsylvania, Ohio, and Illinois produce $3 / 4$ of the pig iron and $9-10$ of the steel. Reasons?

33. Ship-building centers around Delaware and Chesapeake Bays. Reasons?

34. Illinois, Kansas, and Nebraska lead in slaughtering and meat packing. Reasons? What cities lead?

35. Minnesota leads in flour milling. What city leads? Any reason?

36. Massachusetts leads in boot and shoe making. Reasons? Leading cities?

\title{
TO SET YOUR WATCH BY THE SUN
}

\author{
By WILLIS E. JOHNSON, \\ Northern Normal and Industrial School, Aberdeen, S. D.
}

$\mathbb{W}^{\text {H }}$ E laugh at the story of the traveler in the Alps who had recently purchased a fine Swiss watch and when out to observe the sunrise kept looking at his time piece and expressing anxiety lest the appearance of the sun be delayed. It is a poor watch, however, that gains or loses as much time in a day as the sun ordinarily does. Not only is the time of sunrise and sunset constantly varying, but the time elapsing from sun noon to sun noon again is sometimes more and sometimes less than twenty-four hours. To be sure, the sun gains as much in one season as it loses in another, and so, unlike the watch, ultimately comes around exactly "on time."

The reasons why the sun is such an erratic time-keeper are not very difficult to understand but are of too technical a character to come within the limits of this article. The explanation may be found in a mathematical geography or an astronomy. However, that the sun is sometimes fast and sometimes slow, at times as much as sixteen minutes, may be assumed and must be borne in mind if one would set his watch by the world's great time-keeper. The amount which the sun is fast or slow at different dates is shown in the table at the end of this article.

One other fact must claim our attention before we are ready to regulate our timepieces by the noon sun. With a very few exceptions people in the United States do not attempt to keep "sun time," not even the average sun time, but practically all timepieces are regulated according to a system of standard time. According to the present system, which was adopted in this country in 1883, people living east of the Alleghenies set their watches twelve when the shadow is north (if the sun is on time) at the 75 th meridian; timepieces in central United States indicate the average sun time of the 90th meridian; those of the mountain region of the west, that of the 105th meridian; and those of the Pacific seaboard, that of the 120 th meridian. 
Notice now what follows from this keeping of standard time. When the sun in its apparent westward journey looks down upon Boston (longitude $71^{\circ}$ ) and says noon, and the shadow is north, the people of Boston say, "No, it is not 12:00 o'clock yet, and won't be until you reach the 75th meridian." Now it takes the sun four minutes to sweep over one degree of longitude and Boston is four degrees east of the 75th meridian, so sun time in that city is 16 minutes ahead of clock time. When the genial rays of the sun pour down upon Pittsburg and north shadows there indicate that it is noon by the sun, the clocks indicate 20 minutes past $12: 00$, for Pittsburg is $5^{\circ}$ west of the 75th, or standard-time meridian. Sun time at Pittsburg is 20 minutes behind clock time. The case is precisely similar in places which use Central time but which are east or west of the 90th meridian, and in other belts as well. For example, Chicago is $21 / 2^{\circ}$ east of the 90th meridian. The sun time there is thus 10 minutes ( 4 minutes for each degree, and $21 / 2 \times 4 \mathrm{~min} .=10 \mathrm{~min}$.) ahead of clock time. Seattle is $214^{\circ}$ west of the 120 th meridian, from which Pacific time is reckoned, and hence at that city sun time is 9 minutes behind clock time. Philadelphia is on the 75th meridian, hence sun time is the same as clock time. New Orleans and St. Louis are on the 90th meridian and clock time agrees with sun time. Similarly, Denver is on the 105th meridian and the same agreement is shown between the clock and the sun. Now if this is clear, note that the statements in this paragraph are true if clock and sun are "on time."

Jiet us now review the foregoing paragraph and note the effect of the irregularity of the sun. If you are at Boston and the sun is neither fast nor slow, when the shadow is north you may set your watch 16 minutes before 12:00, since sun time is that many minutes faster than standard time there. But on only four days of the year is the sun neither fast nor slow. Suppose the sun is 5 minutes slow; then the shadow will be north 5 minutes later than usual, or 11 minutes before 12:00. Suppose the sun is 5 minutes fast; the shadow will be north 21 minutes before 12:00. Suppose you are at Seattle and want to set your watch by the noon sun when the sun is 14 minutes slow. If the sun were on time, the shadow would be north at 9 minutes past $12: 00$, but, being 14 minutes slow, it will be north 14 minutes later than that, or at $12: 23$. When the shadow is north, under these circumstances, you know your watch should indicate $12: 23$, and set it accordingly.

The general principles now being clear, let us learn how to determine the equation of time, or how fast or slow the sun is, for any day of the year, from the table. The numbers at the top of the columns are the dates, only every fifth day being given. "S" stands for slow and " $F$ " for fast, and the numbers indicate how many minutes the sun is slow or fast on the given date. Thus on January 1 the sun is slow 3.3 minutes, on January 6 it is slow 5.6 minutes. For dates between the 1st and the 6 th, 
a simple calculation will show the proper number. Since the sun is slow 3.3 minutes on the 1 st and 5.6 minutes slow on the 6 th, it must have lost 2.3 minutes in five days, or .46 minute each day. On the 2 nd it will be 3.76 minutes slow, on the $3 r d$ it will be 4.22 minutes slow, etc. We are now ready for the rule:

1. Find the difference between your longitude and your standard time meridian (the 75th if you use Eastern time, the 90 th if you use Central time, etc.).

2. Multiply the number of degrees thus obtained by 4 . This gives the number of minutes by which local time differs from standard time. Add this number to 12:00 o'clock if you are west of the standard time meridian, or subtract it if you are east of it. This gives the time when the shadow is north if the sun is neither fast nor slow.

3. Find the equation of time for the day when you make the experjment. If fast, subtract that time from the answer obtained in step 2 ; if slow, add. This gives you the time when the shadow will be north on that date. Example. Suppose you are at Boston January 1. Longitude of Boston, $71^{\circ}$; standard time meridian used, $75^{\circ}$. Step 1: $75^{\circ}-71^{\circ}=$ $4^{\circ}$. Step 2: $4 \times 4=16$. 12:00-16=11:44. (When the sun is neither slow nor fast the shadow will be north at Boston at 11:44 A. M., eastern standard time.) Step 3: The equation of time for January 1st is 3.5 minutes slow (see table). $11: 44+3.5=11: 471 / 2$, the time when the shadow will be north at Boston on that day.

While the following table is calculated for mean solar noon of $90^{\circ}$ west of Greenwich for the year 1910, it will not vary greatly for several years. The letters $S$ and $F$ indicate whether the sun is slow or fast, the number giving the minutes to the nearest tenth. The equation is given for the 1st, 6th, 11th, 16th, 21st, 26th, and 31st of each month. Thus January 16 the sun is slow 9.8 minutes, or 9 minutes and 48 seconds.

\section{EQUATION OF TIME}

\begin{tabular}{|c|c|c|c|c|c|c|c|c|c|c|c|c|c|}
\hline & 1st & & h & & $\mathrm{h}$ & & $\mathrm{h}$ & & 21 st & & 6 th & & $31 \mathrm{st}$ \\
\hline Tan & 3.5 & $S$ & .5 .8 & $\mathrm{~S}$ & 8.0 & $S$ & 9.8 & $S$ & 11.4 & $\mathrm{~S}$ & 19.7 & & 3.6 \\
\hline$\ldots$ & 13.7 & $\mathrm{~S}$ & 14.2 & $\mathbf{S}$ & 14.4 & $\mathrm{~S}$ & 14.3 & & .8 & $\mathrm{~S}$ & 13.1 & & \\
\hline$\ldots S$ & 12.6 & $\mathbf{S}$ & 11.5 & 5 & 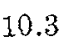 & 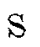 & 8.9 & & 7.4 & 8 & 5.9 & & \\
\hline pr...... & 4.1 & $\mathrm{~S}$ & 2.6 & S & 1.2 & $F$ & 0.1 & & 1.2 & $\mathrm{~F}$ & 2.2 & & \\
\hline Iay .......... & 2.9 & $F$ & 3.5 & $F$ & 3.8 & $\mathrm{~F}$ & 3.8 & $\Gamma$ & 3.6 & $\pi$ & 3.2 & $\mathrm{~F}$ & \\
\hline une.... & 2.5 & $\mathbf{F}$ & 1.7 & 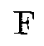 & 0.7 & 3 & 0.3 & & 1.4 & S & 2.5 & & \\
\hline & 3.8 & s & -1.4 & & 5.2 & 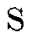 & 5.8 & & $G$ & a & 6.3 & & \\
\hline$\ldots \ldots$ & 6.2 & 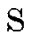 & 5.8 & & 5.1 & $\mathrm{~S}$ & 4.2 & & 3.1 & 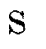 & 1.8 & & \\
\hline$\ldots$ & 0.1 & $F$ & 1.5 & $\mathrm{E}$ & 3.2 & $\mathrm{~F}$ & 5.0 & & 6.8 & $F$ & 8.5 & & \\
\hline$\ldots$ & 10.2 & $F$ & 11.7 & $\mathrm{~F}$ & 3.1 & I. & 14.3 & 1 & 5.2 & F & 5.9 & & \\
\hline$\ldots . . F$ & & $\mathbf{F}$ & 16.3 & & 5.9 & & $15: 2$ & 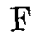 & 4.1 & $\mathrm{~F}$ & 12.7 & & \\
\hline$\ldots \ldots \ldots$ & 11.0 & $\mathrm{~T}$ & 9.0 & & 6.8 & & 4.1 & $\mathrm{~F}$ & 2.0 & $\mathrm{~S}$ & 0.5 & & 0 \\
\hline
\end{tabular}

